\title{
Shifts of visuospatial attention to invisible (metacontrast-masked) singletons: Clues from reaction times and event-related potential
}

\author{
Ulrich Ansorge and Manfred Heumann
}

Department of Psychology, Bielefeld University, Bielefeld, Germany

Received 12.04.2005

Accepted 20.10.2005

\section{Keywords}

Choice reaction time, ERP, vision, attention

\begin{abstract}
In the current study, we tested whether a masked and, thus, invisible singleton-cue captures attention in a stimulus-driven manner or in a top-down contingent manner. The manual RT (Reaction Time) capture effect with the invisible singleton-cue decreased substantially when a match between the singleton-cue and the top-down controlled set of searched-for target features was also decreased. By contrast, with the PCN (Posterior Contralateral Negativity), an electrophysi-
\end{abstract}

ological measure of the capture of visuospatial attention by the invisible singleton-cue, no significant decrement was observed. Taken together, the results support the assumption that an invisible singleton-cue can capture attention in a stimulus-driven manner, and that different delays in the deallocation of attention (i.e., attention is deallocated more efficiently from a cue that does not match the top-down controlled set than from a cue that does match the same set) account for the weaker manual RT capture effect with a set-nonmatching invisible singleton-cue.

\section{INTRODUCTION}

According to one widely held view, nonconscious processes are automatic, stimulus-driven, and do not depend on an individual's intentions (cf. Damian, 2001; McCormick, 1997; Posner \& Snyder, 1975). However, recent evidence challenges this notion. Several lines of research indicate that effects of nonconsciously registered visual stimuli might be contigent upon top-down control settings in the sense that they depend on prior intentions (cf. Ansorge \& Neumann, 2005; Kunde, Kiesel, \& Hoffmann, 2003; Reynvoet, Gevers, \& Caessens, in press; Schlaghecken \& Eimer, 2004; see also Kiesel, Kunde, Pohl, \& Hoffmann, 2006, this issue). Kunde et al., for example, were able to demonstrate effects of invisible word stimuli on RTs (Reaction Times) only if these stimuli matched the intentions of the participants. However, such RT results are at odds with more encompassing measures of the processing of nonconscious information. Kiefer (2002), for instance, found signatures of invisible words on ERPs (Event-Related Potentials) in the absence of any significant effects of these stimuli on RTs.

In the current study, we examined both RTs and ERPs to investigate whether the capture of visuospatial attention by an invisible singleton is top-down contingent or stimulus-driven. A singleton is a stimulus that differs from all the other stimuli in a display by at least one of its features, while the other stimuli in the display are usually nonsingletons that are more similar to each other than to the singleton (Bacon \& Egeth, 1994; Lamy \& Egeth, 2003). Instances of singletons are a circle shown among a multitude of squares, or a red stimulus shown among a multitude of black stimuli.

According to the contingent-involuntary orienting hypothesis, singleton capture (attentional capture by a singleton) is contingent upon the singleton matching a top-

Correspondence concerning this article should be addressed to Ulrich Ansorge, Department of Psychology, Bielefeld University, P.O. Box 100131, D-33501 Bielefeld, Germany. E-mail: ulrich.ansorge@uni-bielefeld.de. 
-down controlled set of searched-for target features (cf. Folk, Remington, \& Johnston, 1992). Support for the contingent-involuntary orienting hypothesis comes from studies that employed a clearly visible singleton as a nonpredictive peripheral cue (Folk \& Remington, 1998, 1999; Folk et al., 1992; Remington, Folk, \& McLean, 2001). Unforeseeable to the participants, a target was shown at one of four possible positions in each trial. Prior to the target, a singleton was presented as a cue at one of the positions. In a valid condition, the singleton-cue was at target position. In an invalid condition, it was at a distance from the target. The singleton-cue was nonpredictive with respect to the likely position of the target. Therefore, participants had no incentive to attend to it as such. Yet, it is known that even under these conditions, if the cue-target interval is not too long (< ca. $300 \mathrm{~ms}$ ), processing time and RT are faster with a valid peripheral cue than with an invalid peripheral cue (cf. Jonides, 1981; Posner, 1980). This validity effect reflects the capture of visuospatial attention by the cue. As a consequence of such capture, attention is already at target position at the onset of the target in the valid condition. By contrast, in the invalid condition, attention needs to be directed to the target after the onset of the latter.

Crucially, Folk and Remington (1998) also manipulated the degree to which the singleton-cue matched the top-down control settings. In line with the contingent-involuntary orienting hypothesis, matching cues captured attention, whereas nonmatching cues did not. Participants were required to report the shape of a target of a known color, say red, while either a green or a red singleton cue was shown in advance of the target. Folk and Remington found that a cue with a target-similar and, therefore, set-matching color captured spatial attention and could not easily be ignored: The set-matching valid cue directed attention to the target, as indicated by a decrease in correct choice RTs relative to RTs with an invalid set-matching cue. By contrast, a cue with a target-dissimilar and, therefore, set-nonmatching color was efficiently ignored. For example, a green cue presented in advance of a red target did not capture spatial attention: Performance was the same in valid and invalid conditions (Folk \& Remington, 1998).

Using clearly visible cues, corresponding top-down contingencies of attentional capture have been found to hold under a variety of different task conditions - specifically, with discrimination of target locations as well as with discrimination of target shapes, and with different singleton-target or cue-target intervals ranging from simultaneous onsets to intervals of several hundred milliseconds (Ansorge \& Heumann, 2003, 2004; Ansorge, Horstmann, \& Carbone, 2005;
Ludwig \& Gilchrist, 2002; Horstmann \& Ansorge, 2006; Remington, Folk, \& McLean, 2001).

Recent research with metacontrast-masked singleton-cues has made it clear that similar top-down contingencies might hold when attention is captured by an invisible singleton (cf. Ansorge, 2004; Ansorge, Heumann, \& Scharlau, 2002; Ansorge \& Neumann, 2001, 2005; Scharlau \& Ansorge, 2003). Metacontrast is an efficient means of masking a visual test stimulus - that is, to reduce its visibility. In metacontrast masking, the visibility of a test stimulus deteriorates due to a spatially adjacent visual mask that follows the test stimulus in close temporal succession (Breitmeyer, 1984; Stigler, 1910). Optimal metacontrast masking is observed with an SOA (Stimulus Onset Asynchrony) of about 30-70 ms between the test stimulus and the mask (cf. Alpern, 1953). Some very efficient metacontrast masking conditions can be used even to completely block a visual test stimulus from accessing conscious perception: Metacontrast masking can be so strong that the test stimulus can no longer be discriminated and becomes invisible. For example, the detection of two bars used as test stimuli can be reduced to chance level under conditions where the masks consist of boxes that have inner contours that fit exactly around the outer contours of the preceding bars (Ansorge, 2003, 2004; Leuthold \& Kopp, 1998; Neumann \& Klotz, 1994).

Despite its invisibility, a metacontrast-masked singleton-cue has the power to capture attention. This is evident, for instance, from studies on prior entry or PLP (Perceptual Latency Priming; cf. Neumann, Esselmann, \& Klotz, 1993; Scharlau, 2002, 2004; Scharlau \& Ansorge, 2003; Scharlau \& Neumann, 2003a, 2003b; Steglich \& Neumann, 2000). PLP is observed when a masked singleton-cue precedes a clearly visible target (that also masks the preceding cue): The perception of the target is facilitated. A validly cued target seems to temporally lead a concomitantly presented, non-cued comparison stimulus (e.g., Scharlau, 2002). As Scharlau and co-workers were able to show, this PLP effect most likely reflects the capture of visuospatial attention (Scharlau, 2002; Scharlau \& Ansorge, 2003; Scharlau \& Neumann, 2003b; see also Scharlau \& Horstmann, 2006, this issue).

What is important in the context of the present study is that capture by an invisible singleton-cue seems to be contingent on top-down control settings. A metacontrast-masked singleton-cue, for example, produces a PLP effect if it has a searched for target-like color or if it has a searched-for target-like shape. The PLP effect is clearly reduced, or it is even absent, however, if this is not the case (cf. Scharlau \& Ansorge, 2003). 
Yet there is an alternative to the contingent-involuntary orienting account. Some authors consider singleton capture to be a stimulus-driven attentional effect (cf. Theeuwes, 1992, 1994, 1996). This assumption is supported by singleton capture under conditions in which top-down feature search is possible (cf. Lamy \& Egeth, 2003; Turatto \& Galfano, 2001). Turatto and Galfano (2001), for example, used red and green nonpredictive singletons and white targets. As a consequence, singleton color did not match the set of searched-for target colors. Yet the set-nonmatching color singleton was found to capture attention.

If it is true that singleton capture is a stimulus-driven effect, how can the difference between the stronger capture effect with a set-matching, as compared with a set-nonmatching, singleton be explained (cf. Ansorge \& Heumann, 2003, 2004; Folk et al., 1992; Gibson \& Kelsey, 1998; Scharlau \& Ansorge, 2003; Yantis \& Egeth, 1999)? It might be accounted for by different delays in attentional deallocation from the singleton (cf. Theeuwes, 1994; Theeuwes, Atchley, \& Kramer, 2000). According to the deallocation explanation, a salient stimulus, such as a color singleton-cue, captures attention in a stimulus-driven manner - that is, regardless of whether or not the singleton-cue matches a top-down controlled set of target features. However, once attention has been captured by the singleton-cue, participants deallocate attention from the irrelevant and non-predictive singleton-cue to prepare for a rapid attention shift to the relevant target (cf. Posner \& Cohen, 1984). Because it is more difficult to tell apart a target-similar singleton or cue from a target than it is to tell apart a target-dissimilar singleton or cue from a target, deallocation has a rapid onset under conditions in which a setnonmatching or a target-dissimilar singleton or cue is used. By contrast, deallocation has a delayed onset under conditions in which a set-matching or a target-similar singleton or cue is shown. With a small but positive interval between the singleton-cue and the target (or the response), it is possible that attentional capture by the set-nonmatching singleton-cue has already given way to deallocation at the time of the target onset (or of the response). Therefore, the validity effect associated with set-nonmatching singleton-cues is reduced or absent. By contrast, if the interval is not too long, attention is still at the position of the set-matching singleton-cue at the onset of the target (or when the response is given), and hence a validity effect is observed. In summary, the deallocation explanation argues that the capture effects produced by matching and nonmatching singleton-cues are initially the same, and that the capture effects associated with a matching singleton-cue simply prevail for a longer duration than those associated with a nonmatching cue.

At present, it seems as if the deallocation of attention cannot explain all cases in which a stronger capture effect is observed with clearly visible matching singleton-cues than with nonmatching singleton-cues (cf. Ansorge et al., 2005; Remington et al., 2001). For example, we analyzed the capture effect as a function of manual RT, and found that the capture effect with a matching singleton was already present among the fast manual responses, whereas capture by a nonmatching singleton trailed somewhat behind. In other words, we did not find evidence of an early processing phase during which the capture effects by the matching and the nonmatching visible singleton were similarly strong (Ansorge et al., 2005). Yet, it could be argued that manual responses are generally too slow to reflect a preceding capture effect in more rapid specific information processing domains, for example, in the saccadic system (cf. Van Zoest, Donk, \& Theeuwes, 2004). Also, little is known about whether similar principles hold in the case of the processing of nonconsciously registered visual information.

In the current study, we tested whether differences between validity effects for set-matching and set-nonmatching metacontrast-masked singleton-cues are due to different amounts of contingent involuntary orienting or whether they reflect different delays of deallocation. To circumvent the shortcomings of only measuring manual RT effects, we recorded ERPs as an encompassing correlate of any information processes, whether in the service of manual responses or not. Research with clearly visible cues has indicated that ERP and RT measures of attentional capture can be dissociated. In particular, evidence for attentional capture can be obtained in ERPs under conditions in which evidence for attentional capture is absent in RTs (cf. Handy, Green, Klein, \& Mangun, 2001). This pattern of results is consistent with a deallocation explanation. According to the deallocation explanation, attentional capture by a nonpredictive or otherwise irrelevant cue should decline as a function of increasing time since cue onset. Therefore, covert ERPs that temporally precede an overt response can reflect attentional capture under conditions in which the corresponding evidence is already absent from the RTs.

The component which we investigated in the present study is a PCN (Posterior Contralateral Negativity). The PCN is a negativity at scalp sites contralateral to the target; it has its maximum at posterior scalp sites (quite often at OL and OR) and a latency of about 150-350 ms post stimulus. It is one of the components which are re- 
lated to the distribution of visuospatial attention. Luck and Hillyard (1994) were the first to identify the conditions required to observe a $\mathrm{PCN}$ (or rather a specific variant of the PCN, which Luck and Hillyard called the "N2pc"): The observation of a PCN requires the use of one relevant, or to-be-attended to, target and one irrelevant, or to-be-ignored distractor, stimulus on opposite horizontal sides of a visual display. The process reflected by the PCN is attentional facilitation in processing the target or attentional inhibition in processing the irrelevant distractor (cf. Eimer, 1996; Luck, Girelli, McDermott, \& Ford, 1997): The fact that a PCN can be evoked by a wide variety of different stimuli, such as "pop-out stimuli", feature singletons (cf. Girelli \& Luck, 1997; Luck \& Hillyard, 1995), targets which are defined by a conjunction of features (cf. Luck \& Hillyard, 1995), invisible singletons (cf. Jaśkowski, Skalska, \& Verleger, 2003; Woodman \& Luck, 2003), or clearly visible but task-irrelevant color singletons (Hickey, McDonald, \& Theeuwes, in press) make it a particularly suitable measure for the purpose of the present study.

In the following experiments, we used a singleton-search paradigm with a clearly visible target singleton and a preceding metacontrast-masked singleton-cue. Across three experiments, we systematically reduced the match between the masked singleton-cue and the set of searched-for target features. On the basis of our previous observations, we expected that an RT capture effect of the masked singleton-cue would decrease as a function of increasing dissimilarity between the cue and the set (cf. Ansorge \& Neumann, 2005). If this matching-to-nonmatching capture difference is due to different amounts of top-down contingent capture, then the PCN effect should follow a similar function. If it is true that a masked singleton-cue only captures attention when it matches the set, a nonmatching singleton-cue should not be attended to from the moment that it appears. As a consequence, a nonmatching masked singleton-cue cannot be expected to give rise to a PCN and an RT effect. However, if the matching-to-nonmatching capture difference is due to deallocation, then we should find more evidence for capture by a nonmatching singleton in the PCN than in the RTs. According to the deallocation explanation, matching-to-nonmatching capture differences build up over time. Because the PCN temporally precedes the overt response, we might find more PCN evidence for attentional capture under conditions in which the corresponding RT evidence is already reduced.

\section{EXPERIMENT 1}

In Experiment 1, we aimed to replicate previous results which showed that a masked singleton-cue that matches the set elicits a PCN and leads to an RT effect (Jaśkowski et al., 2003; see also Jaśkowski, van der Lubbe, Schlotterbeck, \& Verleger, 2002). To that end, we used a masked prime as a singleton-cue. Basically, a prime is a cue which has the potential to activate an incipient response (cf. Eimer \& Schlaghecken, 1998; Klotz \& Neumann, 1999; Leuthold \& Kopp, 1998; Neumann \& Klotz, 1994). In the current study, participants were required to respond to the elevation (i.e., vertical position) of a pair of clearly visible, black target bars on the screen. The target bars were presented at one of four positions (above/right, below/ right, above/left, below/left). A bar above fixation required a right-hand response, and a bar below fixation required a left-hand response (or vice versa, between participants).

Prior to the visible target, a masked, black bar prime was shown as a singleton-cue at one of the positions. Thus, this (shape) singleton-cue matched the set of relevant and searched-for target colors and shapes. In the valid condition, the singleton-cue was at target position. The valid singleton-cue was always response-congruent, as it indicated the same response as the target. In the invalid condition, the singleton-cue was at one of the positions away from the target. Thus, the invalid singleton-cue could be either response-congruent or response-in-congruent with respect to the target. A congruent/invalid singleton-cue was presented at the same elevation as the target and, thus, indicated the same response as the target. An incongruent/invalid singleton-cue was presented at an elevation different from the target and, thus, indicated a different response than the target. We expected to find a response-activation effect of the masked singleton-cue. With a congruent singleton-cue, RT should be lower than with an incongruent singleton-cue. Also, we expected to find an attentional effect of the masked singleton-cue. With a valid singleton-cue, RT should be lower than with an invalid singleton-cue.

Moreover, if the masked singleton-cue captures visuospatial attention, we should observe a PCN located with respect to the horizontal side of the masked singleton-cue. In same-side conditions, the masked singleton-cue and the target were presented on the same horizontal side. Therefore, from its onset, a PCN was expected to be located contralateral to the side of the target. By contrast, in different-side conditions, the masked singleton-cue and the target were presented on opposite horizontal sides. Therefore, the PCN was expected to change its direction over time. At its very onset, the PCN should be more negative contralateral to the side of the masked singleton-cue, and only after the onset of the target should the PCN change its loca- 


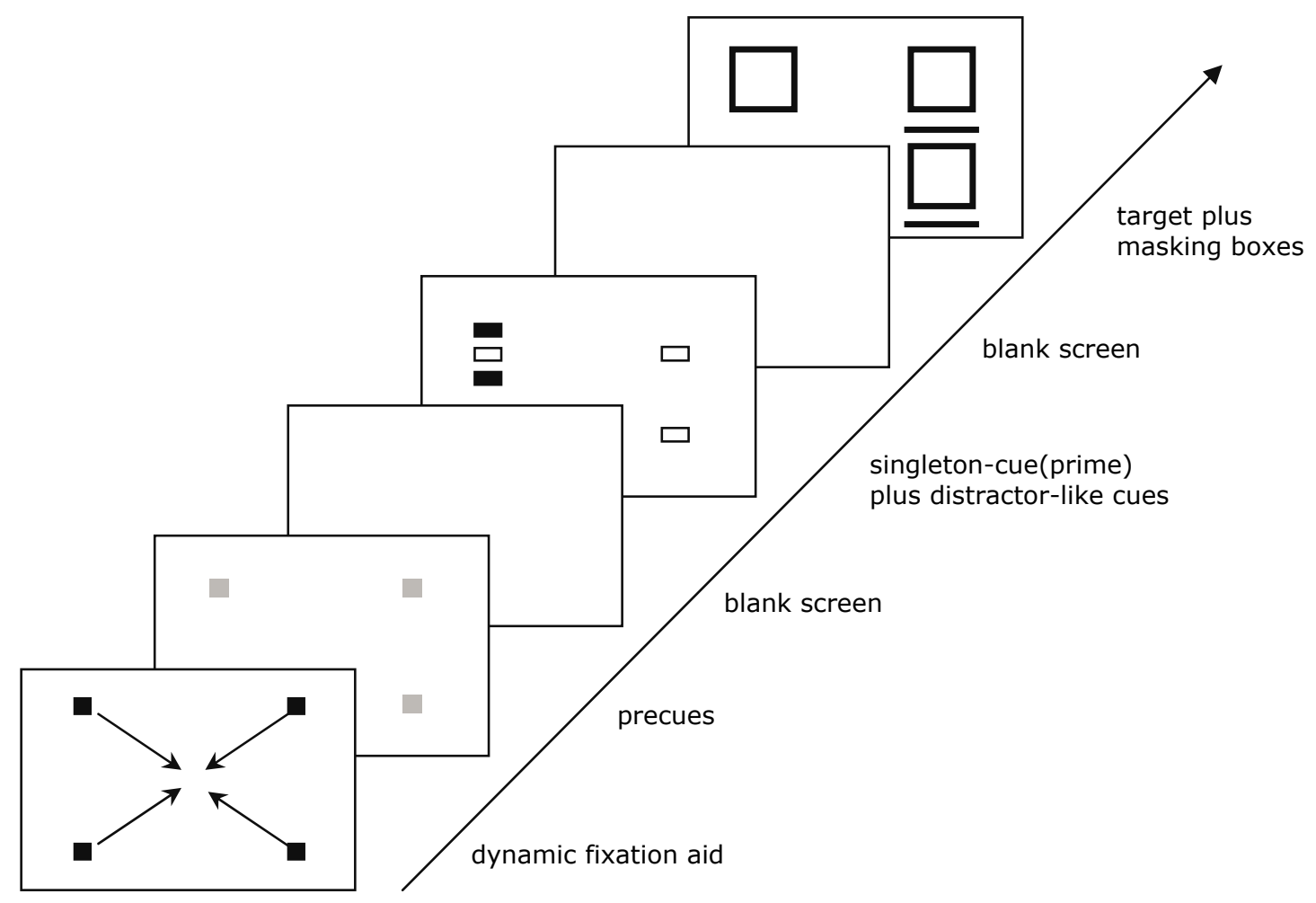

\section{Figure 1}

From bottom to top, succession of events in a trial of Experiment 1. Depicted is an invalid and incongruent trial with the singleton-cue being at a different elevation and on the opposite side as compared with the target. For further details refer to the Method section

tion and be more negative contralateral to the side of the target (cf. Jaśkowski et al., 2003).

Finally, we also wanted to confirm that the singleton-cue was indeed invisible. To that end, we used a discrimination task in which participants were required to indicate in each trial whether a singleton-cue was present or not. Based on previous results with the current stimuli (cf. Neumann \& Klotz, 1994), we expected that participants would not be able to discriminate between the conditions due to the masking of the cues.

\section{Method}

\section{Participants}

Eighteen students (8 female, 10 male) at Bielefeld University, Bielefeld, Germany, with a mean age of 29 years, participated in RT blocks of Experiment 1, and 18 students (12 female, 6 male) of the same population, with a mean age of 27 years participated, in SD (Signal Detection) blocks of Experiment 1. Participants were paid and had normal or corrected-to-normal vision.

\section{Apparatus}

The experiment was controlled by a computer that also collected the data. Stimuli were presented on a 19-inch color monitor. Response buttons were on two tablets, one on either of a chair's armrests. The participants pressed the left and right response buttons with the index fingers of the corresponding hands, and latencies were measured from the target onset to the nearest millisecond. The participants sat in an electrically shielded, sound attenuated, and dimly lit room, $150 \mathrm{~cm}$ in front of the screen, with their line of gaze straight ahead and their hands resting on the response devices.

\section{Stimuli}

The sequence of events in a trial is shown in Figure 1. Stimuli were presented black on a bright background. The target and the singleton-cue each consisted of two horizontally parallel lines which were presented at one of four positions, above/right, below/right, above/left, and below/left. Each of the positions was $5.7^{\circ}$ of visual angle from the screen centre. The singleton-cue had the same shape as the target but it was smaller than the target.

\section{Procedure in RT blocks}

A fixation spot was presented at the centre of the screen throughout the whole session, apart from when it was turned off briefly between the recording epochs of one trial and the start of the next trial. During the 
time that the fixation point was turned off, participants could initiate a break by simultaneously pressing both response keys. With a varying interval after the onset of the fixation spot, four small precues $\left(0.55^{\circ} \times 0.6^{\circ}\right)$ were shown for $15 \mathrm{~ms}$, one precue at each of the four possible positions. After an ISI (Inter Stimulus Interval) of $15 \mathrm{~ms}$, the cue-singleton display was presented for $15 \mathrm{~ms}$. It consisted of four small outline boxes (stroke width of the outline $=0.06^{\circ}$ ), one box at each of the positions, and a target-like singleton-cue (a small pair of bars) at only one of the positions. The singleton-cue's bars were $0.5^{\circ}$ long and $0.12^{\circ}$ wide. Finally, a target array was presented for $1,000 \mathrm{~ms}$ after an ISI of $45 \mathrm{~ms}$, resulting in a cue-target SOA of $60 \mathrm{~ms}$. The target consisted of a pair of larger bars. It was equally likely at one of the four positions. Concomitantly with the target, four masking boxes were shown, one at each of the four positions. The size of the boxes in the target array $\left(0.9^{\circ} \times 1.4^{\circ}\right.$ with an outline width of $\left.0.18^{\circ}\right)$ was such that the inner contours of the masking boxes fitted exactly around the outer contours of the singleton-cue. The inter-trial interval varied from 3,290 ms to $3,695 \mathrm{~ms}$.

In a quarter of the trials, a masked singleton-cue preceded the target at its position. This was the same-side/congruent or valid condition. In another quarter of the trials, a masked singleton-cue was presented at the same elevation (i.e., in the same vertical hemifield) as the target but on the opposite horizontal side. This was the different-side/congruent condition. In the remaining half of the trials, the masked singleton-cue was shown with an elevation different from the target. These were the incongruent conditions. Again, the incongruent singleton-cue either was presented at the same horizontal side as the target (same-side/incongruent condition) or the incongruent singleton-cue and the target were on opposite horizontal sides (different-side/incongruent condition).

Target and singleton-cue were presented with equal probability at each of the four positions, and the singleton-cue was nonpredictive: It neither predicted the likely position of the target nor the likely response. Participants responded to the position of the target. Half of the participants pressed a right-hand response button if the target was above fixation, and a left-hand response button if the target was below fixation. This S-R (Stimulus-Response) mapping was reversed for the other half of the participants.

After instruction and brief practice of approximately 40 trials, participants went through 800 experimental trials. Together with the mounting of the electrodes and short rests (every 100 trials by default, and whenever the participants felt they needed a rest) the experiment took about one hour.

\section{Procedure in SD blocks}

In half of the trials of the SD blocks, no singleton-cue was presented (neutral condition). In these trials, only the precues and the small outline boxes were shown prior to the target display. The other half of the trials comprised congruent and incongruent conditions (equally probable). Participants were instructed to look for the masked singleton-cue and to judge whether or not it was presented. They were required to press one key to indicate that they had detected a singleton-cue and another key to indicate that they did not detect a singleton-cue. A detection task (i.e., a decision whether the singleton-cue was present or absent) instead of a localization task (i.e., a decision whether the singleton-cue was left or right) was used in the SD block to prevent application of task sets from RT to SD blocks and, hence, minimize the chance that nonconscious motor activation effects of masked singleton-cues contaminated measures of SD performance.

A detection judgment was required in each of the trials of the SD task. Participants were encouraged to guess when they did not see whether or not a singleton-cue was presented. Prior to the SD block, the sequence of events was shown in slow-motion to give the participants an idea of what to search for. The two possible S-R mappings for present vs. absent judgments were balanced across participants. No ERPs were recorded in the SD blocks. Otherwise the procedure was exactly the same as that in the RT blocks.

\section{EEG data recording and analysis}

Horizontal and vertical EOG (Electroculogram), and EEG (Electroencephalogram) were recorded with $\mathrm{Ag} / \mathrm{AgCl}$ electrodes. Recordings were obtained from scalp sites F3, Fz, F4, Cz, P3, Pz, P4, and Oz of the international 10-20 system, and from $\mathrm{C}^{\prime}$ and $\mathrm{C}^{\prime}$ (located $1 \mathrm{~cm}$ anterior of $\mathrm{C} 3$ and $\mathrm{C} 4$ ), and from $\mathrm{OL}$ and $\mathrm{OR}$ (located half-way in between $\mathrm{O} 1$ and $\mathrm{T} 5$ and in between $\mathrm{O} 2$ and T6). The electrode signals were referenced to an average of the left and right earlobes. The ground electrode was placed on the forehead. EEG was recorded with a rate of 250 samples per second and low-pass filtered at $40 \mathrm{~Hz}$. Separate ERPs for the different conditions were averaged, time-locked to the onset of the singleton-cue. Therefore, throughout, ERP latencies are from the singleton-cue's onset. Amplitudes of the potentials were differences to the activity in a $100 \mathrm{~ms}$ pre-cue baseline. Prior to the data analysis, trials with incorrect responses, ocular artifacts (blinks or large eye movements), muscle artifacts, or amplifier saturation were excluded. To that end, we removed any trials that met one of the following 


\section{Table 1}

Reaction Times (in Milliseconds), and Error Rates (in percent; given in parentheses) as a function of Condition (Same Side: cue on same side as the target; Different Side: cue on different side than the target; Same Elevation: cue at same elevation as the target; Different Elevation: cue at different elevation than the target) and Experiment (1-3). Exp.: Experiment.

Exp.

\begin{tabular}{|c|c|c|c|c|c|}
\hline & $\begin{array}{l}\text { Valid/Same } \\
\text { Side/Same } \\
\text { Elevation }\end{array}$ & $\begin{array}{l}\text { Different } \\
\text { Side/Same } \\
\text { Elevation }\end{array}$ & $\begin{array}{l}\text { Same Side/ } \\
\text { Different } \\
\text { Elevation }\end{array}$ & $\begin{array}{l}\text { Different } \\
\text { Side/ } \\
\text { Different } \\
\text { Elevation }\end{array}$ & $\begin{array}{l}\text { Maximum } \\
\text { Cueing Effect }\end{array}$ \\
\hline 1 & $440(5.3)$ & $468(6.3)$ & $477(6.3)$ & $475(7.5)$ & $33(2.2)$ \\
\hline 2 & $554(5.9)$ & $560(6.0)$ & $562(5.7)$ & $565(6.5)$ & $11(0.6)$ \\
\hline 3 & $570(7.5)$ & $577(8.3)$ & $576(7.4)$ & $578(8.3)$ & $8(0.8)$ \\
\hline
\end{tabular}

criteria: (1) amplitudes exceeding $100 \mu \mathrm{V}$ at any recording channel, (2) amplitudes exceeding $50 \mu \mathrm{V}$ at one of the EOG channels, (3) amplitudes of $0 \mu \mathrm{V}$ during the complete recording epoch at any channel.

In the following, we restrict our report to the ERLS (Event-Related Lateralizations) from OL/OR. ERLS were derived by subtracting averages ipsilateral to the target from averages contralateral to the target. Note that in contrast to many previous studies (cf. Woldorff, 1993), the activity which was evoked by the singleton-cue was not filtered out. Thus, in the current study, ERLs reflected the amount of activation to one side as a function of both stimuli, the masked, nonpredictive, peripheral singleton-cue and the relevant target.

ERLs were computed by first computing two averages for each condition and subject; one for trials in which the cue appeared on the left side, one for trials with a right cue. For each of these averages we computed the difference of the contralateral and the ipsilateral electrode, and then averaged those differences for left and right averages.

\section{Results}

\section{SD task}

$d^{\prime}$ was calculated individually for each participant (Green \& Swets, 1966). A $t$ test of the average $d^{\prime}$ across participants against zero revealed a residual but very low capacity to detect the masked singleton-cue $\left(d^{\prime}=0.09, t[17]=2.43, p<.05\right)$.

\section{RT task}

See Table 1 for the results of all experiments. Of the 18 participants, 3 had to be excluded due to an excessive (> 70\%) amount of blink or eye movement artifacts. Out of all 12,000 responses, 5 were excluded because they were faster than $100 \mathrm{~ms}$ or slower than $1,000 \mathrm{~ms}$. Separate ANOVAs (Analyses of Variance) on RT and error rates, with cue-target position (same-side/congruent [valid] vs. different-side/congruent vs. same-side/incongruent vs. different-side/incongruent) as a variable, yielded the following results. Where appropriate, here and in later analyses, degrees of freedom were corrected by the Greenhouse-Geisser coefficient $\varepsilon$, and the corrected alpha levels are given (Hays, 1988). There was a significant main effect of cue-target position in the RTs, $F(3,42)=41.60, p<.01$. RT was lower in same-side/congruent condition (440 ms) than in different-side/congruent condition (468 ms), $t(14)=7.8, p<.01$, and than in both incongruent conditions (same-side: $477 \mathrm{~ms}$, different-side: $475 \mathrm{~ms}$ ) both $t \mathrm{~s}(14)>7.7$, both $p s<.01$. RTs in different invalid conditions were not significantly different from one another, $t(14)<2.4, p=.03$ (Bonferroni corrected significant a level $=.017$ ).

The effect of cue-target position was not significant in an analysis of the arc-sine transformed error rates, $F(3,42)<1.0$. However, numerically, error rate effects were in a similar direction as RT effects: Error rate was lower in same-side/congruent conditions (5.3\%) than it was in the different-side/congruent condition $(6.3 \%)$, and it was highest in the incongruent conditions (same-side: 6.3\%, different-side: 7.5\%). Therefore, a speed-accuracy trade-off cannot account for the RT effect of the masked singleton-cue.

\section{ERLS}

As can be seen in Figure 2, beginning at $150-200 \mathrm{~ms}$ post cue, ERLs started to become negative in the same-side conditions, but initially were positive in the different-side conditions, whereas after about 300-350 ms, ERLs were negative in all of the conditions. This observation is consistent with an attentional capture effect of the masked singleton-cue that has a maximum at about $200 \mathrm{~ms}$ to $250 \mathrm{~ms}$ after cue onset, with attention being shifted to the side of the target in the sameside conditions, but to a side opposite of the target in the different-side conditions. To test the effect of the cue on the lateralized potentials, we computed the average amplitude for each subject in each condition in a window ranging from $200 \mathrm{~ms}$ to $250 \mathrm{~ms}$ after cue 


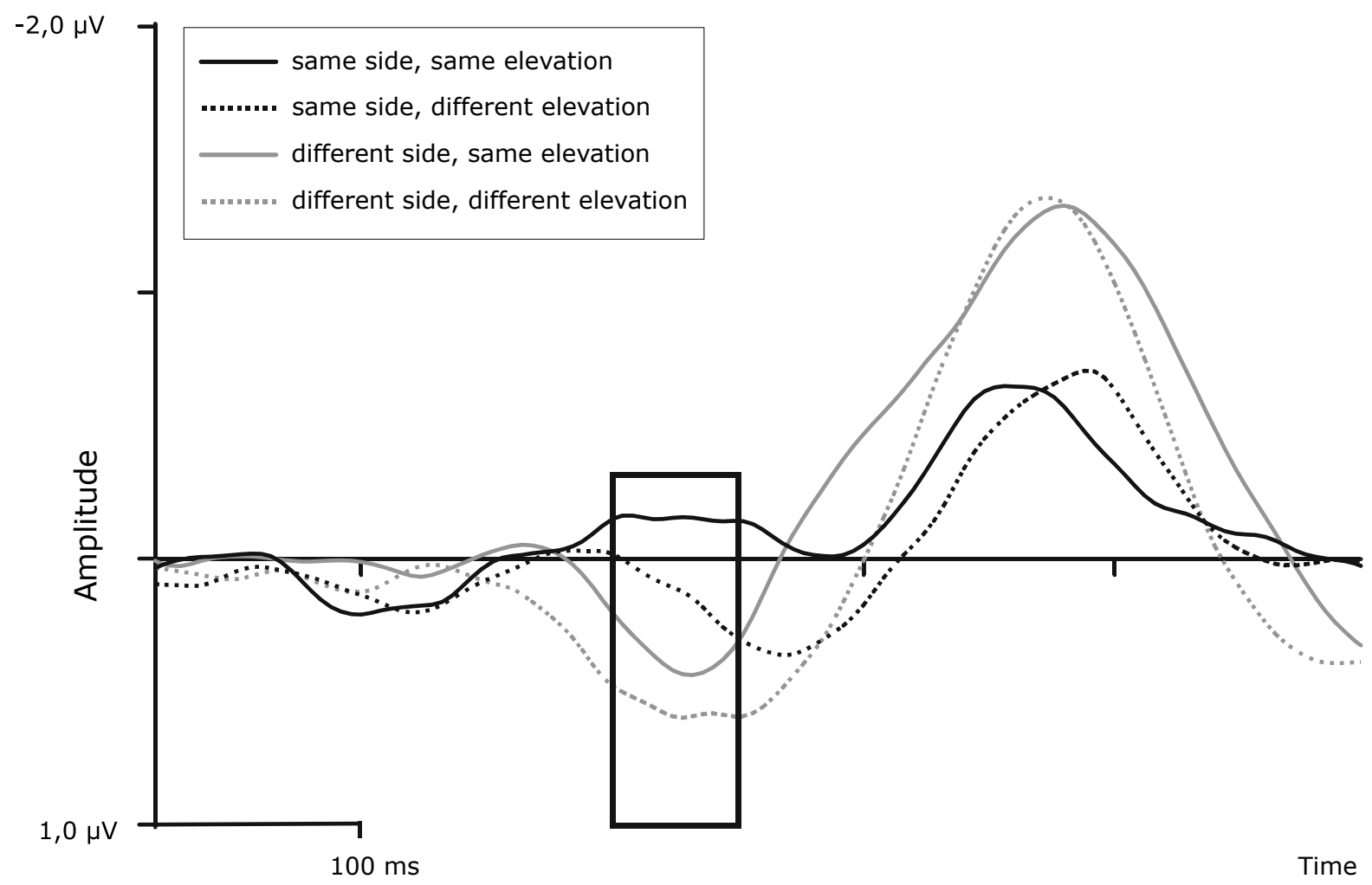

Figure 2

PCNs (Posterior Contralateral Negativities) at lateral occipital electrodes (OL/OR) as a function of cue-target side relation (same or different) and cue-target elevation relation (same or different) in Experiment 1 . The masked singleton-cue was presented at a time point corresponding to the position of the $y$ axis. Mean amplitudes were averaged across a temporal window indicated by the rectangle.

onset. The average values were then subjected to an ANOVA with the variables side (same vs. different) and elevation (same vs. different, i.e. congruent vs. incongruent). The ANOVA revealed a significant main effect of side, $F(1,14)=6.5 ; p<.05$. Neither the main effect of elevation/congruence, $F(1,14)=1.0$; $p=.33$, nor the interaction, $F(1,14)=1.07, p=.32$, was significant.

\section{Discussion}

Results corroborated the assumption that a masked singleton-cue captures attention. A valid singleton-cue (same-side/congruent condition) reduced RT relative to an invalid singleton-cue (all other conditions), although the singleton-cues were very well masked and, thus, almost completely invisible. In comparison to previous investigations, the RT validity effect was reduced, and we found no reliable RT advantage in the invalid/congruent condition relative to the invalid/incongruent condition (Ansorge \& Neumann, 2005; Neumann \& Klotz, 1994). Possibly, the necessity to keep the eyes at fixation in the present ERP study but not in the past investigations created a dual-task condition at the ex- pense of an optimal processing and a maximal effect of the masked primes (cf. Ansorge, 2004).

The most important result, however, is that attentional capture by the masked singleton-cue was also evident in the PCN. When the masked singleton-cue was on the same horizontal side as the target, the PCN was more negative at a location contralateral to the target, right from the onset of the component. However, when the masked singleton-cue was on the horizontal side opposite of the target, at PCN onset, the component was more negative at a location contralateral to the masked singleton-cue. Only somewhat later did the PCN change its location and become more negative on the horizontal side contralateral to the target (see Figure 2). Thus, we replicated results of Jaśkowski et al. (2003) with the current procedure. What is more, the PCN (amplitude) was not affected by response-congruence. This finding corroborates the conclusion that the PCN effect reflects attentional processes rather than sensorimotor effects of the masked singleton-cue.

Yet from Experiment 1 alone, one cannot tell whether the RT effect and the PCN effect of the masked singleton-cue were due to bottom-up capture or to contingent involuntary orienting. In particular, due to 
a close match between the features of the singleton-cue and the set of relevant target features, the capture effect might reflect top-down contingent involuntary orienting of attention to the singleton-cue (cf. Ansorge, 2004; Ansorge \& Neumann, 2001, 2005; Scharlau \& Ansorge, 2003; Woodman \& Luck, 2003). This possibility was tested in the following experiments.

\section{EXPERIMENT 2}

In Experiment 2, we tested whether the attentional capture effect of the masked singleton-cue is topdown contingent or whether it is stimulus-driven. To that end, we reduced the similarity between the target and the singleton-cue. Thus, in the present experiment, the masked singleton-cue matched less well to the set of target features. Previous observations suggest that, under these conditions, the RT capture effect of the masked singleton-cue is strongly reduced or absent (cf. Ansorge et al., 2002; Ansorge \& Neumann, 2001, 2005). Therefore, it seems as if involuntary orienting of attention to the masked singleton-cue is contingent on the singleton-cue matching the top-down control settings.

Crucially, however, this conclusion is based on RT evidence. Yet mean RT might be a measure which is not particularly sensitive to the stimulus-driven capture effect of the nonmatching singleton because RT pinpoints the effect at a relatively late point in time. According to a deallocation explanation, the nonmatching singleton-cue captures attention but, thereafter, attention is quickly deallocated away from the nonmatching singleton-cue (cf. Theeuwes, 1994). Therefore, we might find more evidence for the stimulus-driven capture effect of the nonmatching singleton-cue in a measure such as the PCN, which temporally precedes the overt response.

\section{Method}

\section{Participants}

Thirty-four students (19 female, 15 male) at Bielefeld University, Bielefeld, Germany, with a mean age of 27 years participated in Experiment 2. Participants were paid, and had normal or corrected-to-normal vision.

\section{Apparatus, stimuli, procedure, recording, and analysis}

These were the same as in the previous experiment, except for the following changes. First, in each trial, one of the clearly visible target bars was red; either the bar below the masking box or the bar above the masking box. Participants were required to respond to the position of the red target bar relative to that of the black box and target bar at the same relative screen position (and not to the position of the two bars relative to the screen center as before). Half of the participants had to press the left key if the red bar was above the box and the right key if the red bar was below the box. The other half of the participants had an inverted S-R mapping. Otherwise the procedure was exactly the same as in Experiment 1. In particular, the masked singleton-cue again consisted of two black bars. Therefore, the match between the set of searched-for target features (a red bar) and the features of the singleton-cue (black bars) was greatly reduced. Second, we did not use an SD task. A former study suggests that using red as the color of one of the target bars does not affect performance in an SD task (cf. Ansorge \& Neumann, 2005).

\section{Results}

\section{RTs}

See Table 1 for the results of all experiments. The data of 8 of the participants had to be excluded due to artifact rates above $70 \%$, leaving the data of 26 participants. Out of all remaining responses, $2.3 \%$ were excluded because they were faster than $100 \mathrm{~ms}$ or slower than $1,000 \mathrm{~ms}$. Separate ANOVAs on RT and error rates, with cue-target position (same-side/ same-elevation [valid] vs. different-side/same-elevation vs. same-side/different-elevation vs. different-side/different-elevation) as a variable, yielded the following results. There was a significant main effect of position in the RTs, $F(3,75)=12.5, p<.01$. RT was lower in (valid) same-side/same-elevation (554 ms) conditions than in all the other (invalid) conditions (same-side/different-elevation: RT $=562 \mathrm{~ms}$; different-side/same-elevation: RT = $560 \mathrm{~ms}$; differentside/different-elevation: $\mathrm{RT}=565$; all $t \mathrm{~s}$ [25] > 3.1, all $p s<.01)$. There were no significant differences between the invalid conditions, all $t s<2.3$, all $p s>.03$ (Bonferroni corrected significant a level $=.017$ ). Also, the effect of cue-target position was not significant in an analysis of the arc-sine transformed error rates, $F(3,75)=1.1, p=.3$.

\section{ERLS}

See Figure 3 for the results. As in Experiment 1, we tested the effect of the cue with a 2-way ANOVA which yielded the following results: The main effect of side was significant, $F(1,25)=12.0 ; p<.01$, and neither the main effect of elevation nor the interaction were significant, both $F \mathrm{~s}(1,25)<1$. 


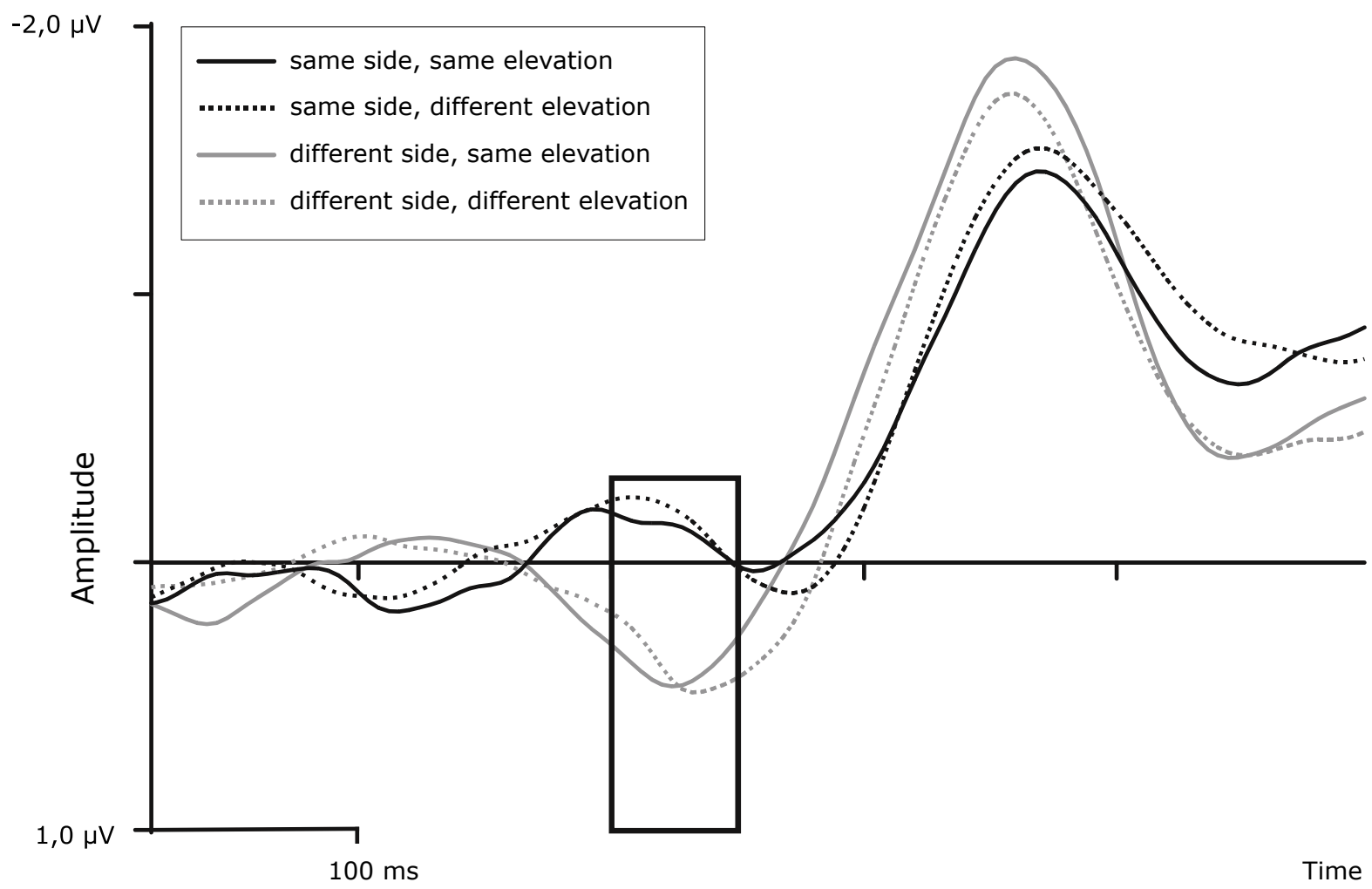

Figure 3

PCNs (Posterior Contralateral Negativities) at lateral occipital electrodes (OL/OR) as a function of cue-target side relation (same or different) and cue-target elevation relation (same or different) in Experiment 2. The masked singleton-cue was presented at a time point corresponding to the position of the $y$ axis. Mean amplitudes were averaged across a temporal window indicated by the rectangle.

\section{Discussion}

In the current experiment, we obtained a residual attentional capture effect of the nonmatching singleton-cue: There was a reliable $11 \mathrm{~ms}$ RT advantage in the valid (same-side/same-elevation) condition as compared with all the invalid conditions. This result is not in line with that of a previous investigation in which we found no significant capture effect under very similar conditions (cf. Ansorge \& Neumann, 2005). Possibly, the larger data sample per average in the current, relative to our former, investigation increased the power sufficiently to yield a significant residual capture effect. In any case, decreasing the match between the masked singleton-cue and the set of searched-for target features from Experiment 1 to 2 apparently decreased the RT capture effect: The RT effect of the masked singleton-cue was strongly reduced (to $11 \mathrm{~ms}$ ) by $22 \mathrm{~ms}$ as compared with that of the preceding experiment (33 ms), $F(3,39)=22.8, p<.01$, for an interaction of Side/Elevation $\times$ Experiments ( 1 vs. 2 ).

It might be objected that the slightly more demanding task (i.e., the discrimination of relative fine spatial differences between target positions) in the present, as compared with the preceding, experiment could have increased RTs so that short-lived effects of the invisible stimulus (cf. Greenwald, Draine, \& Abrams, 1996; Rossetti, 1998) had a higher probability of having decayed at the time of the overt response. However, three lines of evidence suggest that the passage of time between an invisible stimulus and an overt response is not sufficient to explain the results. First, similar RT effects with invisible stimuli have been found with spatially compatible and spatially incompatible responses, although the latter are consistently slower than the former (cf. Leuthold \& Kopp, 1998; Neumann \& Klotz, 1994). Second, RT effects with invisible stimuli are the same for different parts of the RT distribution (cf. Experiment 3 of Ansorge, 2004). Third, RT effects with invisible stimuli are equally strong for vocal and manual responses, although the former are slower than the latter (cf. Ansorge, Klotz, \& Neumann, 1998; Eimer \& Schlaghecken, 2001).

It is most important to note, however, that, in contrast to the RT capture effect of the masked singleton-cue, the PCN effect of the singleton-cue was not significantly reduced in the current experiment relative to in the previous experiment $(F \mathrm{~S}<1$, 
for interactions of Side $\times$ Experiments, and of Side $\times$ Elevation $\times$ Experiments). Once again, the PCN which was evoked by the singleton-cue was evident from the reversal of PCN polarity in the different-side conditions but not in the same-side conditions (see Figure 3 ). Therefore, it might well be that the matching-to-nonmatching difference in the RT capture effect observed between Experiments 1 and 2 was due to different delays of deallocation rather than to different amounts of top-down contingent involuntary orienting.

In contrast to the PCN amplitude results, visual inspection of Figures 2 and 3 suggests that top-down settings might have at least affected PCN latencies to some extent: PCN latency in same-side/different-elevation conditions was probably delayed relative to the other singleton conditions in Experiment 1 but not in Experiment 2. Arguably, the PCN latency difference reflects significantly delayed RTs in incongruent same-side/different-elevation conditions of Experiment 1, a tendency toward a specific RT effect which was not observed in Experiment 2. This pattern, although not supported by a significant interaction of the PCN amplitudes, seems to be in line with recent findings indicating that PCN latencies are correlated with different search strategies and visual discrimination requirements (cf. Wolber \& Wascher, 2003, 2005). As already mentioned, the present spatial discrimination task was slightly more difficult than in the preceding experiment.

\section{EXPERIMENT 3}

In Experiment 3, we attempted to reduce the RT capture effect of the masked singleton-cue further. To that end, we once again reduced the similarity between the set of searched-for target features and the masked singleton-cue. The target was presented at only two of the four possible positions, whereas the masked singleton-cue was again equally likely to be shown at each of the four positions. Previous observations suggest that, under these conditions, an RT capture effect of a visible cue should further diminish because this manipulation decreased the match between the cue locations and the set of searched-for target locations (cf. Ansorge \& Heumann, 2003).

Expectations were the same as before. If involuntary orienting of attention to the masked singleton-cue is contingent on a match of the singleton-cue to the top-down control settings, then RT and PCN capture effects should be reduced. If, however, deallocation is responsible for the reduced RT capture effect, then we should find more evidence for attentional capture by the masked singleton-cue in the temporally preceding PCN.

\section{Method}

\section{Participants}

Eighteen students (7 female, 11 male) at Bielefeld University, Bielefeld, Germany, with a mean age of 26 years participated in Experiment 3. Participants were paid, and had normal or corrected-to-normal vision.

\section{Apparatus, stimuli, procedure, recording, and analysis}

These were the same as in Experiment 2, except for the following change. Known to the participants, the number of possible positions of the red target bar was reduced from four to two. For half of the participants, the target was either at a position above/left or below/ right of fixation. For the other half of the participants, the target was either at a position above/right or below/left of fixation.

\section{Results}

\section{RTS}

See Table 1 for the results of all experiments. The data of three participants had to be excluded from the analyses due to too many artifacts in the EEG data according to the same criteria as in Experiments 1 and 2. Separate ANOVAs on RT and error rates, with cue-target position (same-side/same elevation [valid] vs. different-side/same-elevation vs. same-side/different-elevation vs. different-side/different-elevation) as a variable, yielded the following results. There was no significant main effect of position in RTs and error rates, $F(3,42)=1.8 ; p=.16$. RT was about the same in (valid) same-side/same-elevation (570 ms) conditions as compared with all the other (invalid) conditions (different-side/same-elevation: RT = 577 ms; same-side/different-elevation: RT = $576 \mathrm{~ms}$; different-side/different-elevation: $\mathrm{RT}=578 \mathrm{~ms}$ ). The analysis of the arc-sine transformed error rates also yielded no significant effect, $F(3,42)<1$.

\section{ERLS}

See Figure 4 for the results. The two-way ANOVA of the average amplitudes in the window 200-250 ms after cue onset yielded a significant main effect for the side variable, $F(1,14)=6.9 ; p<.05$, no significant main effect of elevation, and no significant interaction, both $F s(1,14)<1$. 


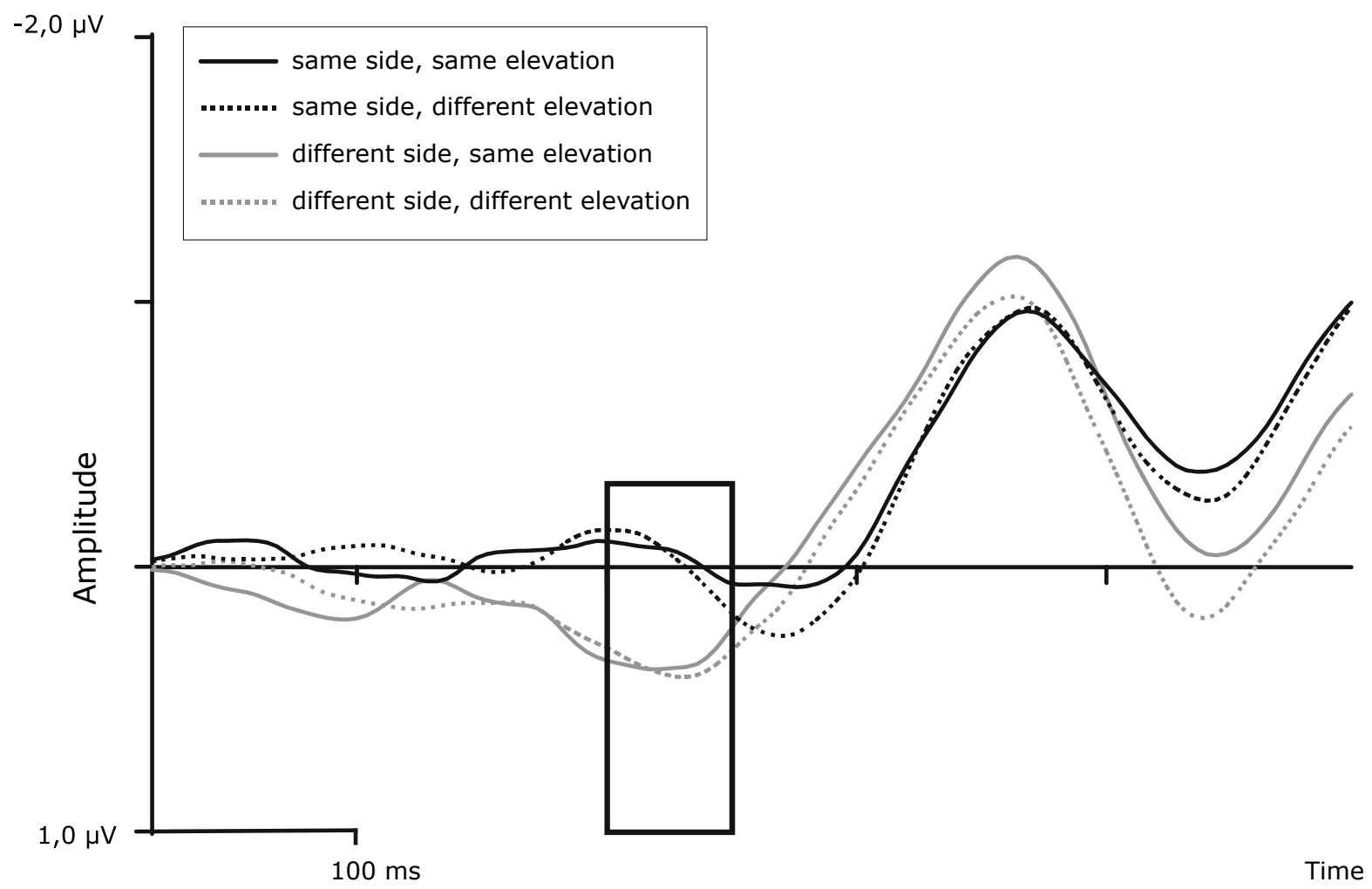

\section{Figure 4}

PCNs (Posterior Contralateral Negativities) at lateral occipital electrodes (OL/OR) as a function of cue-target side relation (same or different) and cue-target elevation relation (same or different) in Experiment 3. The masked singleton-cue was presented at a time point corresponding to the position of the $y$ axis. Mean amplitudes were averaged across a temporal window indicated by the rectangle.

To compare the results for the PCN across experiments, we performed an ANOVA including the results of Experiments 1-3, with the two within-participant variables side (same vs. different) and elevation (same vs. different), and the between-participants variable experiment ( 1 vs. 2 vs. 3 ). The results confirmed that side had a strong effect on the data, $F(1,53)=22.2$; $p<.01$, that variables experiment, $F(2,53)<1$, and elevation had no reliable effect, $F(1,53)<1$, and that the effect of side was not significantly modified by the variable experiment, $F(2,53)<1$, for the interaction of Side $\times$ Experiment. The other interactions were also nonsignificant, all $F \mathrm{~s}<1$.

\section{Discussion}

The match between the set of the searched-for target features and the masked singleton-cue was reduced in Experiment 3 relative to in Experiments 1 and 2. As a consequence, the RT capture effect of the masked singleton-cue was virtually abolished. However, as in Experiments 1 and 2, we obtained PCN evidence for the orienting of attention toward the masked singleton-cue. This result is clearly much more consistent with a deallocation account of the matching-to-nonmatching singleton-cueing effect difference than with a contingent-involuntary-orienting explanation.

\section{GENERAL DISCUSSION}

In the present study, we investigated whether an invisible singleton-cue captures attention in a stimulus-driven manner or whether an involuntary orienting of attention to the invisible singleton-cue is contingent on a match between the singleton and the top-down controlled set of searched-for target features. From Experiment 1 to Experiment 3, we systematically decreased the degree of the match between the invisible singleton-cue and the set of searched-for target features. In Experiment 1, the invisible singleton-cue had the same color as the target and in each trial it was presented at one of the possible target locations. Thus, the match was good. As a consequence, and in keeping with previous observations, effects of attentional capture were reflected both in overt performance (cf. Ansorge \& Neumann, 2005) and in a PCN (cf. Jaśkowski et al., 2003). In valid conditions, in which cue and target were presented at the same position, RT performance was facilitated relative 
to performance in all invalid conditions. Also, in same-side conditions, the invisible singleton-cue and the target were presented both on the same horizontal side. In these conditions, right from the onset of the PCN, this component was more negative at scalp sites which are contralateral to the target. By contrast, in different-side conditions, the invisible singleton-cue was on the opposite horizontal side to the target. In these conditions, at its onset, the PCN was more negative at scalp sites contralateral to the invisible singleton-cue (see Figures 2-4). Only after some time, the PCN reverted its polarity to become more negative at scalp sites which are contralateral to the target (cf. Jaśkowski et al., 2003).

In Experiment 2, the invisible singleton-cue had a color which was different from that of the target. Thus, the singleton-cue matched less well the set of searched-for target features than in Experiment 1. As a consequence, and in keeping with previous observations, the RT capture effect of the singleton-cue was reduced (cf. Ansorge et al., 2002; Ansorge \& Neumann, 2005). By contrast, the PCN, taken as an alternative measure of the attentional capture by the singleton-cue was present in fairly similar amounts in Experiments 1 and 2. Finally, in Experiment 3, the color of the invisible singleton-cue was different from that of the target, and in half of the trials the singleton-cue was presented at a position at which the target was never shown. Thus, the match between the features of the singleton-cue and the set of searched-for target features was further decreased as compared with the previous experiment, and, as a consequence, the RT capture effect of the invisible singleton-cue was virtually abolished. However, we still found evidence for attentional capture by the invisible singleton-cue in the PCN.

In summary, the results support the assumption that the invisible singleton-cue captured attention in a stimulus-driven manner - that is, regardless of whether or not the singleton-cue matched the participants' intentions. This observation is consistent with many results showing that clearly visible singletons also capture attention, irrespective of whether or not they match a set of searched-for target features (cf. Bacon \& Egeth, 1994; Lamy \& Egeth, 2003; Theeuwes, 1994; Turatto \& Galfano, 2001; Van Zoest et al., 2004). This stimulus-driven capture effect was reflected in the $\mathrm{PCN}$. The results are also in line with the assumption that backward or metacontrast masking of a visual stimulus leaves an initial transient response to the onset of the stimulus virtually unaffected (cf. Breitmeyer, 1984; Breitmeyer, Ogmen, \& Chen, 2004; Haynes, Driver, \& Rees, 2005; see also van Aalderen-Smeets, Oostenveld, \& Schwarzbach, 2006, this issue).
However, it is not necessary that the overt responses also reflect this stimulus-driven capture effect. The reason for this is that the overt response temporally lags behind the PCN capture effect. Thus, the RT effect might be more vulnerable to deallocation: Participants have more time to deallocate their attention from the invisible singleton-cue before they make an overt manual response than before the PCN is generated.

In conclusion, top-down control over the processing of invisible information is seemingly exerted during a two-phase process. During the first processing phase, an invisible singleton automatically captures attention due to its salience (cf. McCormick, 1997). During a second phase, however, if the singletontriggered process is not supported by information contained in a visible target stimulus, the shifting of attention to the invisible singleton is subject to selfinhibition of the attentional shift. According to this explanation, de- or reallocation of visuospatial attention is due to a sequence of processes very similar to the self-inhibition of incipient responses activated by invisible stimuli (cf. Eimer \& Schlaghecken, 1998; Klapp \& Hinkley, 2002; Schlaghecken \& Eimer, 2002; see also Schlaghecken \& Sisman, 2006, this issue; for more refined conceptions of the responsible mechanism, see Lleras \& Enns, 2004, 2005; Verleger, Jaśkowski, Aydemir, van der Lubbe, \& Groen, 2004).

However, it is also clear that the masked singleton-cue in the current investigation created a more salient signal at one position than the concomitantly presented stimuli (i.e., the small boxes) at the remaining positions. Therefore, it is also possible that the observed PCN effect (partly) reflects initial stimulus-driven cortical activation by the masked singleton-cue instead of attentional capture by the cue (cf. Näätänen \& Michie, 1979; Valle-Inclán, 1996). In future studies, it should be tested whether the observed pattern of results generalizes to conditions with concomitant and equally salient matching, and less-matching, metacontrast-masked nontarget stimuli on opposite sides.

\section{Acknowledgements}

Ulrich Ansorge and Manfred Heumann, Department of Psychology, Bielefeld University, Bielefeld, Germany.

Supported by Deutsche Forschungsgemeinschaft Grants Ne 366/6-1 and Ne 366/4-3 to Odmar Neumann. We thank Andrea Kiesel, Werner Klotz, Wilfried Kunde, Odmar Neumann, Ingrid Scharlau, and four anonymous reviewers for excellent comments on earlier versions of the current paper, Eva Böcker for assistance in conducting the experiments, and Heike Hartwig-Jakobs for help with the final preparation of the manuscript. 


\section{References}

Alpern, M. (1953). Metacontrast. Journal of the Optical Society of America, 43, 648-657.

Ansorge, U. (2003). Asymmetric influences of temporally vs. nasally presented masked visual information: Evidence for collicular contributions to nonconscious priming effects. Brain and Cognition, 51, 317-325. |WwW

Ansorge, U. (2004). Top-down contingencies of nonconscious priming revealed by dual-task interference. Quarterly Journal of Experimental Psychology, 57A. 1123-1148. Www

Ansorge, U., \& Heumann, M. (2003). Top-down contingencies in peripheral cuing: The roles of color and location. Journal of Experimental Psychology: Human Perception and Performance, 29, 937-948. Www

Ansorge, U., \& Heumann, M. (2004). Peripheral cuing by abrupt-onset cues: The role of color in S-R corresponding conditions. Acta Psychologica, 116, 115-143. $\mid w W w$

Ansorge, U., Heumann, M., \& Scharlau, I. (2002). Influences of visibility, intentions, and probability in a peripheral cuing task. Consciousness and Cognition, 11, 528-545. Www

Ansorge, U., Horstmann, G., \& Carbone (2005). Top-down contingent capture by color: Evidence from RT distribution analyses in a manual choice reaction task. Acta Psychologica, 120, 243-266. |WwW

Ansorge, U., Klotz, W., \& Neumann, O. (1998). Manual and verbal responses to completely masked (unreportable) stimuli: Exploring some conditions for the metacontrast dissociation. Perception, 27, 1177-1189. WwW

Ansorge, U., \& Neumann, O. (2001). Intentions determine the effect of nonconsciously registered visual information: Evidence for direct parameter specification in the metacontrast dissociation. Proceedings of the AISB '01 Symposium on nonconscious intelligence: from natural to artificial (pp. 1-8). York, UK: AISB.

Ansorge, U., \& Neumann, O. (2005). Intentions determine the effect of invisible metacontrast-masked primes: Evidence for top-down contingencies in a peripheral cueing task. Journal of Experimental Psychology: Human Perception and Performance, 31, 762-777. Www

Bacon, W. F., \& Egeth, H. E. (1994). Overriding stimulus-driven attentional capture. Perception \& Psychophysics, 55, 485-496. |WwW

Breitmeyer, B. G. (1984). Visual masking: An integrative approach. Oxford, UK: Oxford University Press.

Breitmeyer, B., Ogmen, H., \& Chen, J. (2004). Unconscious priming by color and form: Different processes and levels. Consciousness and Cognition, 13, 138-157.
Damian, M. F. (2001). Congruity effects evoked by subliminally presented primes: Automaticity rather than semantic processing. Journal of Experimental Psychology: Human Perception and Performance, 27, 154-165. Www

Eimer, M. (1996). The N2pc component as an indicator of attentional selectivity. Electroencephalography and Clinical Neurophysiology, 99, 225-234. Www

Eimer, M., \& Schlaghecken, F. (1998). Effects of masked stimuli on motor activation: Behavioral and electrophysiological evidence. Journal of Experimental Psychology: Human Perception and Performance, 24, 1737-1747. $\underline{\underline{w W} \mid}$

Eimer, M., \& Schlaghecken, F. (2001). Response facilitation and inhibition in manual, vocal, and oculomotor performance: Evidence for a modality-unspecific mechanism. Journal of Motor Behaviour, 33, 16-26. $\mid \underline{w W \mid}$

Folk, C. L., \& Remington, R. W. (1998). Selectivity in distraction by irrelevant featural singletons: Evidence for two forms of attentional capture. Journal of Experimental Psychology: Human Perception and Performance, 24, 847-858. WwW

Folk, C. L., \& Remington, R. W. (1999). Can new objects override attentional control settings? Perception \& Psychophysics, 61, 727-739. [ww

Folk, C. L., Remington, R. W., \& Johnston, J. C. (1992). Involuntary covert orienting is contingent on attentional control settings. Journal of Experimental Psychology: Human Perception and Performance, 18, 1030-1044. |www

Gibson, B. S., \& Kelsey, E. M. (1998). Stimulus-driven attentional capture is contingent on attentional set for displaywide visual features. Journal of Experimental Psychology: Human Perception and Performance, 24, 699-706. |www

Girelli, M., \& Luck, S. J. (1997). Are the same attentional mechanisms used to detect visual search targets defined by color, orientation, and motion? Journal of Cognitive Neuroscience, 9, 238-253.

Green, D. M., \& Swets, J. A. (1966). Signal detection theory and psychophysics. New York: Wiley.

Greenwald, A. G., Draine, S. C., \& Abrams, R. L. (1996, September 20). Three cognitive markers of unconscious semantic activation. Science, 273, 1699-1702. $\underline{\mathrm{WWW}}$

Handy, T. C., Green, V., Klein, R. M., \& Mangun, G. R. (2001). Combined expectancies: Event-related potentials reveal the early benefits of spatial attention that are obscured by reaction time measures. Journal of Experimental Psychology: Human Perception and Performance, 27, 303-317. |Www 
Haynes, J.-D., Driver, J., \& Rees, G. (2005). Visibility reflects dynamic changes of effective connectivity between V1 and fusiform cortex. Neuron, 46, 811-821. Www

Hays, W. L. (1988). Statistics (4th ed.). New York: Holt, Rinehart and Winston.

Hickey, C., McDonald, J. J., Theeuwes, J. (in press). Electrophysiological evidence of capture of visuospatial attention. Journal of Cognitive Neuroscience.

Horstmann, G., \& Ansorge, U. (2006). Attentional shifts to rare singletons. Visual Cognition, 13, 1-31.

Jaśkowski, P., Skalska, B., \& Verleger, R. (2003). How the self controls its "automatic pilot" when processing subliminal information. Journal of Cognitive Neuroscience, 15, 911-920. |Www|

Jaśkowski, P., van der Lubbe, R. H. J., Schlotterbeck, E., \& Verleger, R. (2002). Traces left on visual selective attention by stimuli that are not consciously identified. Psychological Science, 13, 48-54. [WwW

Jonides, J. (1981). Voluntary versus automatic control over the mind's eye's movement. In J. B. Long \& A. D. Baddeley (Eds.), Attention and performance IX (pp. 187-203). Hillsdale, NJ: Erlbaum.

Kiefer, M. (2002). The N400 is modulated by unconsciously perceived masked words: Further evidence for a spreading activation account of N400 priming effects. Cognitive Brain Research, 13, 27-39. $\mid \underline{w w \mid}$

Kiesel, A., Kunde, W., Pohl, C., \& Hoffmann, J. (2006). Priming from novel masked stimuli depends on target set size. Advances in Cognitive Psychology, 2, 37-45

Klapp, S. T., \& Hinkley, L. B. (2002). The negative compatibility effect: Unconscious inhibition influences reaction time and response selection. Journal of Experimental Psychology: General, 131, 255-269. |www

Klotz, W., \& Neumann, O. (1999). Motor activation without conscious discrimination in metacontrast masking. Journal of Experimental Psychology: Human Perception and Performance, 25, 976-992.

Kunde, W., Kiesel, A., \& Hoffmann, J. (2003). Conscious control over the content of unconscious cognition. Cognition, 88, 223-242. (WwW

Lamy, D., \& Egeth, H. E. (2003). Attentional capture in singleton-detection and feature-search modes. Journal of Experimental Psychology: Human Perception and Performance, 29, 1003-1020. WwW

Lleras, A., \& Enns, J. (2004). Negative compatibility or object updating? A cautionary tale of mask-dependent priming. Journal of Experimental Psychology: General, 133, 475-493.

Lleras, A., \& Enns, J. (2005). Updating a cautionary tale of masked priming: A reply to Klapp (2005). Journal of Experimental Psychology: General, 134, 436-440.
Leuthold, H., \& Kopp, B. (1998). Mechanisms of priming by masked stimuli: Inferences from event-related brain potentials. Psychological Science, 9, 263-269.

Luck, S. J., Girelli, M., McDermott, M. T., \& Ford, M. A. (1997). Bridging the gap between monkey neurophysiology and human perception - an ambiguity resolution theory of visual selective attention. Cognitive Psychology, 33, 64-87. Www

Luck, S. J., \& Hillyard, S. A. (1994). Spatial filtering during visual search: Evidence from human electrophysiology. Journal of Experimental Psychology: Human Perception and Performance, 20, 1000-1014.

Luck, S. J., \& Hillyard, S. A. (1995). The role of attention in feature detection and conjunction discrimination: An electrophysiological analysis. International Journal of Neuroscience, 80, 281-297. [WwW

McCormick, P. A. (1997). Orienting attention without awareness. Journal of Experimental Psychology: Human Perception and Performance, 23, 168-180. WwW Näätänen, R., \& Michie, P. T. (1979). Early selective-attention effects on the evoked potential: A critical review and reinterpretation. Biological Psychology, 8 , 81-136. WwW

Neumann, O., Esselmann, U., \& Klotz, W. (1993). Differential effects of visual-spatial attention on response latency and temporal-order judgment. Psychological Research/Psychologische Forschung, 56, 26-34. Www

Neumann, O., \& Klotz, W. (1994). Motor responses to nonreportable, masked stimuli: Where is the limit of direct parameter specification? In C. Umiltà \& M. Moscovitch (Eds.), Attention and performance XV: Conscious and nonconscious information processing (pp. 123-150). Cambridge, MA: MIT Press.

Posner, M. I. (1980). Orienting of attention. Quarterly Journal of Experimental Psychology, 32, 3-25. WwW

Posner, M. I., \& Cohen, Y. (1984). Components of visual orienting. In H. Bouma \& D. G. Bouwhuis (Eds.), Attention and performance $X$ : Control of language processes (pp. 531-556). Hillsdale, NJ: Erlbaum.

Posner, M. I., \& Snyder, C. R. R. (1975). Attention and cognitive control. In R. L. Solso (Ed.), Information processing and cognition (pp. 55-85). The Loyola symposion. Hillsdale, $\mathrm{NJ}$ : Erlbaum.

Remington, R., Folk, C. L., \& McLean, J. P. (2001). Contingent attentional capture or delayed allocation of attention? Perception \& Psychophysics, 63, 298-307. www

Reynvoet, B., Gevers, W., \& Caessens, B. (in press). Unconscious primes activate motor codes through semantics. Journal of Experimental Psychology: Learning, Memory, and Cognition. Www 
Rossetti, Y. (1998). Implicit short-lived motor representations of space in brain damaged and healthy subjects. Consciousness and Cognition, 7, 520-558. WWw

Scharlau, I. (2002). Leading, but not trailing, primes influence temporal order perception: Further evidence for an attentional account of perceptual latency priming. Perception \& Psychophysics, 64, 1346-1360. |WWW

Scharlau, I., \& Ansorge, U. (2003). Direct parameter specification of an attention shift: Evidence from perceptual latency priming. Vision Research, 43, 1351-1363. WWW

Scharlau, I., \& Horstmann, G. (2006). Perceptual latency priming and illusory line motion: Facilitation by gradients of attention? Advances in Cognitive Psychology, 2, 87-97. ACP

Scharlau, I., \& Neumann, O. (2003a). Perceptual latency priming by masked and unmasked stimuli: Evidence for an attentional interpretation. Psychological Research/Psychologische Forschung, 67, 184-196. |wWw

Scharlau, I., \& Neumann, O. (2003b). Temporal parameters and time course of perceptual latency priming. Acta Psychologica, 113, 185-203. $\mid \underline{\mathrm{ww}}$

Schlaghecken, F., \& Eimer, M. (2002). Motor activation with and without inhibition: Evidence for a threshold mechanism in motor control. Perception \& Psychophysics, 64, 148-162. WwW

Schlaghecken, F., \& Eimer, M. (2004). Masked stimuli can bias "free" choices between response alternatives. Psychonomic Bulletin \& Review, 11, 463-468. WwW

Schlaghecken, F., \& Sisman, R. (2006). Low-level motor inhibition in children: Evidence from the negative compatibility effect. Advances in Cognitive Psychology, 2, 7-19 ACP

Steglich, C., \& Neumann, O. (2000). Temporal, but not spatial, context modulates a masked prime's effect on temporal order judgment, but not on response latency. Psychological Research/Psychologische Forschung, 63, 36-47. WwW

Stigler, R. (1910). Chronoptische Studien über den Umgebungskontrast. Pflüger's Archiv für die gesamte Physiologie, 134, 365-435.

Theeuwes, J. (1992). Perceptual selectivity for color and form. Perception \& Psychophysics, 51, 599-606. Www

Theeuwes, J. (1994). Stimulus-driven capture and attentional set: Selective search for color and visual abrupt onsets. Journal of Experimental Psychology: Human Perception and Performance, 20, 799-806. Www
Theeuwes, J. (1996). Perceptual selectivity for color and form: On the nature of the interference effect. In A. F. Kramer, M. G. H. Coles, \& G. D. Logan (Eds.), Converging operations in the study of visual selective attention (pp. 297-314). Washington, DC: APA.

Theeuwes, J., Atchley, P., \& Kramer, A. F. (2000). On the time course of top-down and bottom-up control of visual attention. In S. Monsell \& J. Driver (Eds.), Attention and Performance XVIII (pp. 105-125). Cambridge, MA: MIT Press.

Turatto, M., \& Galfano, G. (2001). Attentional capture by color without any relevant attentional set. Perception \& Psychophysics, 63, 286-297. [Www

Valle-Inclán, F. (1996). The locus of interference in the Simon effect: an ERP study. Biological Psychology, 43, 147-162. $\underline{\underline{w W w} \mid}$

van Aalderen-Smeets, S. I., Ostenveld, R., \& Schwarzbach, J. (2006). Investigating neurophysiological correlates of metacontrast masking with magnetoencephalography. Advances in Cognitive Psychology, 2, 21-35 ACP

Van Zoest, W., Donk, M., \& Theeuwes, J. (2004). The role of stimulus-driven and goal-driven control in saccadic visual selection. Journal of Experimental Psychology: Human Perception and Performance, 30, 746-759. $\mid \underline{w W \mid}$

Verleger, R., Jaśkowski, P., Aydemir, A., van der Lubbe, R.H.J., \& Groen, M. (2004). Qualitative differences between conscious and non-conscious processing? On inverse priming induced by masked arrows. Journal of Experimental Psychology: General, 133, 494-515. |Ww|

Wolber, M., \& Wascher, E. (2003). Visual search strategies are indexed by event-related lateralizations of the EEG. Biological Psychology, 63, 79-100. Www

Wolber, M., \& Wascher, E. (2005). The posterior contralateral negativity as a temporal indicator of visuospatial processing. Journal of Psychophysiology, 19, 182-194.

Woldorff, M. G. (1993). Distortion of ERP averages due to overlap from temporally adjacent ERPs: Analysis and correction. Psychophysiology, 30, 98-119. Www

Woodman, G. F., \&Luck, S. J. (2003). Dissociationsamong attention, perception, and awareness during object-substitution masking. Psychological Science, 14, 605-611. $\mid \overline{w w \mid}$

Yantis, S., \& Egeth, H. E. (1999). On the distinction between visual salience and stimulus-driven attentional capture. Journal of Experimental Psychology: Human Perception and Performance, 25, 661-676. [WWw 